\title{
Influencing Rural Entrepreneurs' Participation in Training Programs in the East Mamprusi District of Ghana
}

\author{
Daniel A. Bagah, Moses Dumayiri, Gordon Terkpeh Sabutey* \\ University for Development Studies, Wa Campus, Ghana \\ *sabuttjoy@yahoo.com
}

\begin{abstract}
The objective of this study is to identify the determinants of rural entrepreneurs' participation in training programs with empirical evidence from the East Mamprusi District in the northern region of Ghana. A semi-structured questionnaire was used to obtain data from 120 owners of Small and Medium Scale Enterprises via a multistage sampling process. Logistic regression was used to analyze the data. The study identifies several factors to have significant influence on the likelihood of participation. These include entrepreneur's socio-demographic features, access to services and past experience acquired in their business operations. Government, Non-governmental Organizations and Civil Society Organizations should, therefore, put more effort in widening the scope of participation in entrepreneurial skills development training. Appropriate attention should be given to gender, age, education, past experience, membership to association and media of advertisement since they are the factors that drive entrepreneurial motivation to participate in training programs. Rural entrepreneurs should develop the initiative to form associations where information on training needs can easily reach them. Any training intervention should also target young entrepreneurs to have more participants. These results have implications for entrepreneurship development in least developed countries.
\end{abstract}

Keywords: Rural Entrepreneurs, Participation, Training Programs, East Mamprusi District, Logistic regression

\section{Introduction}

In recent years, it has been acknowledged that small and medium enterprises (SMEs) can positively influence the economic growth of developing countries (Kayanula and Quartey, 2000). The concern of many development partners is therefore, to develop entrepreneurship in emerging economies. This is because entrepreneurship is one of the most important requirements for enterprise development in the $21^{\text {st }}$ century (Lashgarara et al., 2011). Entrepreneurship is an individual effort of turning ideas into action (European Commission, 2009) which stimulates employment hence a key issue for poverty reduction (Hussain et al., 2014). This however, requires some kind of education or training. The role of training and development of entrepreneurship have been recognized by several studies. A number of studies (Lashgarara et al., 2011; Glaub \& Frese, 2011; Vijayalakshmi, 2014; Hussain et al., 2014) believe that training programs are necessary for entrepreneurs' skills development. In Ghana, about 90\% registered companies are micro, small and medium scale enterprises (Mensah, 2004). These enterprises normally employ less than 29 people as small scale or between 30 and 100 people as medium scale enterprise (Quartey, 2003). The results of the 2000 Population and Housing Census (PHC) showed that about $80 \%$ of the economically active population in Ghana work in the informal sector (Ghana Statistical Service, 2008). This consists of major trade group such as textile, apparel and furnishing, building and material moving which takes persons aged 15 and older as apprentices. Beer (2012) therefore, indicates that training is the link from having a successful business to a thriving one.

The increasing role of household enterprises in the Ghanaian economy attracted past and present governments' attention in the provision of training needs. Graduates from formal educational training often target the formal sector for employment opportunities (Baah-Boateng, 2004) hence the fundamental objective of the Ghana vision 2020 was to reduce poverty via business creation and compliment entrepreneurs' effort with apprentice training. Government has therefore, established institutions in support of this objective, (among them include the National Board for Small Scale Industries (NBSSI), GRATIS Foundation, and Rural Enterprise Project (Mark, 2012)). These interventions aim at providing training in employable skills for small business creation. Besides, there are also about 900 private consultancy firms in 
Ghana delivering commercial technical service to SMEs (Commonwealth Secretariat, 2010). Priority intervention for the Ghana Poverty Reduction Strategy was to increase access to education and training at all levels. The private sector and civil society organizations are expected to play the role of supportive training and skills improvement (MoFA, 2007). This is a key strategy to mainstream gender training in the informal sector. In the East Mamprusi District, several institutions offer training for entrepreneurs with different areas of focus (see Table 1).

Table 1: Institutions and their Area of Support in East Mamprusi District

\begin{tabular}{|c|c|}
\hline Institution & Training Service \\
\hline Rural Enterprise Project (REP) & $\begin{array}{lllll}\begin{array}{l}\text { Identification, formation, registration } \\
\text { entrepreneurs }\end{array} & \text { and training of } \\
\end{array}$ \\
\hline Business Advisory Centre (BAC) & Entrepreneurship training for Small Scale Enterprises \\
\hline $\begin{array}{l}\text { Partners in Rural Empowerment and } \\
\text { Development (PARED) }\end{array}$ & Training of non-farm enterprises" entrepreneurs \\
\hline Community Banks & Training and formation of groups Business advice \\
\hline $\begin{array}{l}\text { CARE International/ Community } \\
\text { Initiative for Food Security (CIFS) }\end{array}$ & $\begin{array}{l}\text { Training on resource mobilization, Technology transfer, } \\
\text { Developing Business plans, Training on gender participation }\end{array}$ \\
\hline Technoserve & $\begin{array}{l}\text { Training on resource mobilization and Developing Business } \\
\text { plans }\end{array}$ \\
\hline
\end{tabular}

Source: Joseph (2010)

Evidence from Table 1 implies that stakeholders consisting of both government and non-governmental organizations have their focus among other things on developing skills required to raise entrepreneurship in many parts of the country. Such initiatives have been extended to the hinterlands such as the East Mamprusi District. Despite Government, Civil Society Organization and Non-governmental Organizations effort to increase skills and productivity of SMEs by providing training intervention to all parts of the country, entrepreneurs' participation in these programs in the hinterland is believed to be low. It has been observed that more than $50 \%$ of women owned businesses in their respective communities but never received any business training (Beer, 2012). Besides, empirical literature on SMEs in Ghana exclusively left out what drives rural entrepreneurs' participation in training programs. The objective of this study is therefore, to identify the determinants of rural entrepreneurs' participation in training programs with empirical evidence from the Mamprusi East District in the northern region of Ghana.

\section{Literature Review}

The role of training in the development of the informal sector of the economy has been noticed by several empirical studies. This is because training programs help develop creativity of entrepreneurs (BascavusogluMreau et al., 2013). Cooney (2012) maintains that training can be in the form of mentoring. Such mentors train entrepreneurs to have access to networks. The mentor acts as a role model and reinforces the belief of what ambition to achieve. Audretch (2012) pinpoints the role of training and enhancement of human capital as a policy intervention that can promote high firm growth. According to him such training needs should include the development of managerial skills to successfully manage rapidly growing firms. Past studies such as Henriquez et al. (2001) support this proposition. In his view, entrepreneurs are required to follow a management training course to ensure the viability of a new business. This may include out-of-school training for entrepreneurship which has been particularly successful at the tertiary level. Ercan et al. (2010) therefore, recommend that stakeholders in SMEs development should organize certificate training programs for entrepreneurs; their content should include: teaching the use of technological devices such as computers, teaching participants to read and write and providing sales and marketing courses to potential entrepreneurs.

Failures of entrepreneurs activities often results from insufficient training needs. A number of studies in many parts of the developing world observe this. In Kenya, Hassan and Mugambi (2013) identify low level of training as a major challenge facing women entrepreneurs. Papzan et al. (2013) therefore, pinpoint the need for specific training for young entrepreneur to increase their efficiency of production. In the developing world, this basically consist of short and long term vocational courses to improve upon traditional methods. 
In their empirical investigation, Aremu and Adeyemi (2011) maintain that technical inefficiency of SMEs in Nigeria results from lack of training programs for entrepreneurs. As a result, entrepreneurial courses are introduced in all their tertiary institutions to provide business skills to students (Garba et al., 2013). Efforts to identify determinants of entrepreneurs' participation in training programs in other countries yield varied successes. Heckman and Smith (2003) point out that awareness of program eligibility is what cause variation in participation. This suggests that stakeholders who offer training services to clients must first convince them on the program eligibility. Lashgarara et al. (2011) highlight the role of the participation features while Glaub and Frese (2011) concentrate on the training content. Glaub and Frese (2011) maintain that different training content have different facets of business success. This training content according to Ercan et al. (2010) should include teaching the entrepreneur to read and write and in some instances train them on the use of technological devices such as computers.

Personal characteristics sometimes influence the decision of entrepreneurs to participate in a training program. Lashgarara et al. (2011) observation in Iran supports this claim. Determinants of participation according to them include personal skills, and psychological characteristics. Besides, Turcotte et al. (2002) observation in Canada place emphasis on human capital as a significant factor. They explain that permanent workers participate more than temporary ones. This observation is cogent as it is less risky to invest in skills development in permanent work than in temporary. They also indicate that worker with post-secondary education often participate in training programs than those with no or lower educational status. Workers who use computers were observed to have relatively higher propensity of attending more than those not using computers. Xiao and Tsang (2001) observation in China confirm that educated entrepreneurs have higher likelihood of attending a job training programs than those with lower education. In Germany, Fritsche (2012) provides consistent results with previous related studies. He maintains that level of education and fulltime employment all have positive influence on participation in job training program. Huj and Smith (2001) share similar results on the effect of education. This therefore, brings to the fore the role of human capital in devising strategies for entrepreneur participation in training programs.

Other personal features such as gender play a significant influential role in participation in training programs. Turcotte et al. (2002) in their observation maintain that men in the informal sector have higher probability of participation than their women counterparts. Besides, Fritsche (2012) observes a U-shape effect of age on participation. Technically, age has a quadratic relationship with participation in training program. This implies that the desire of people to participate decreases with age to a particular point and begins to increase as the age of the person increases. An earlier study conducted by Huj and Smith (2002) maintains a definite stand on the quadratic effect of age on participation. They identify the turning point to be 20 years. They however observed an inverted U-shape effect where the ages of 11 to 13 have strong positive effect on participation but participation begins to decrease after age 20. According to Cooney (2012), the entrepreneur must be motivated to grow the business with peer mentoring from successful entrepreneurs. These are considered as necessary conditions for participation and business development. This suggests that a mentee can develop the willingness for participation in a training program if that was the habit for the mentor. Akanbi (2013) acknowledge this from his study. He indicates that parents in Africa often wish to expose their children to the line of business and occupation. Children with entrepreneur parents therefore, have relatively high propensity of imitating their fathers. The culture of participating in training programs by their parents may be handed over to them.

\section{Methodology}

Data: Data were obtained from a survey conducted in the East Mamprusi District in 2013. The district is located to the north- eastern part of Ghana. To the north it shares boundaries with the Talensi- Nabdam district, Bawku West and Garu Tempane districts and to the east Bunkpurugu- Yunyoo district. It is bordered to the west by West Mamprusi and the south by Gusheigu districts. The district has a land mass of 10,659 sqkm, representing 2.4 percent of the total land mass of the region (East Mamprusi District Assembly, 2012). Respondents were selected via the multi-stage sampling procedure. The selection involved two stages using simple random sampling technique. The first stage involves selection of study community. Six communities were selected and they are Jawani, Gbangu, Nagbo, Sakogu, Gbandabila and Tamboku. On the second stage, 20 respondents were selected from each of the six communities to give a sample size of 120. Questionnaires 
were administered to the respondents covering demographic characteristics of rural entrepreneurs and their participation in job training programs.

Analytical Framework: Participation in a training programme is conceptualised via microeconomic theory of consumer utility maximization. A rational consumer chooses to maximize his/her utility by consuming a particular commodity or service. The probability of an entrepreneur to attend a training programme is influenced by the utility derived from the training service. An entrepreneur's decision to participate or not therefore, yields a binary response variable; taking a value of 1 if an ith respondent ever participated in a programme and 0 if otherwise. Gujarati (2008) indicates that the logistic regression is often used to model binary choice responses. The cumulative logistic distribution function is specified as:

$$
P_{i}=\frac{1}{1+e^{-Z_{i}}}=\frac{e^{z_{i}}}{1+e^{z_{i}}}
$$

Where: $P_{i}$ is the probability of an individual to participate in a training program

$$
Z_{i}=\beta_{0}+\beta_{i} X_{i}
$$

Where: $X_{i}=$ Vector of explanatory variables

$\beta_{0}=$ Vector of constant term

$\beta_{i}=$ Vector of logistic regression coefficient

As $\mathrm{Z}$ ranges from $-\infty$ to $\infty, P_{i}$ ranges from 0 to 1 . The probability of non-participation is $1-P_{i}$.

Where: $\quad 1-P_{i}=1-\frac{e^{z_{i}}}{1+e^{z_{i}}}$

Simplifying equation (3) gives:

$$
1-P_{i}=\frac{1+e^{Z_{i}}-e^{Z_{i}}}{1+e^{Z_{i}}}=\frac{1}{1+e^{Z_{i}}}
$$

The odd ratio in favor of participation is:

$$
\frac{P_{i}}{1-P_{i}}=\frac{e^{Z_{i}}}{1+e^{Z_{i}}} * \frac{1+e^{Z_{i}}}{1}=e^{Z_{i}}
$$

Taking natural $\log$ of equation (5) gives:

$$
\ln \left(\frac{P_{i}}{1-P_{i}}\right)=Z_{i}
$$

Substituting for $Z_{i}$ in (6) gives:

$$
\ln \left(\frac{P_{i}}{1-P_{i}}\right)=\beta_{0}+\beta_{i} X_{i}+U
$$

The relative effect of each explanatory variable on the likelihood that an entrepreneur participates in a training program is given by the marginal effect as:

$$
\frac{\partial\left(P_{i}\right)}{\partial\left(X_{i}\right)}=\beta_{i}[\bar{P}(1-\bar{P})]
$$

Where: $\bar{P}$ is the mean of the dependent variable. An empirical specification of the model for participation in training program is expressed as:

$\ln \left(\frac{P_{i}}{1-P_{i}}\right)=\beta_{0}+\beta_{1} G E N+\beta_{2} A G E+\beta_{3} A G E S Q+\beta_{4} M A R I D+\beta_{5} H S I Z E+\beta_{6} E D U+\beta_{7} E X P+\beta_{8} E X P S Q+$ $\beta_{9} A S S O C+\beta_{10} C R E D I T+\beta_{11} I N F O+U$

Table 2 illustrates the variables definition, measurement and hypothesized relationships.

\section{Results and Discussion}

Summary Statistics: The results of the survey indicate that about $60 \%$ of the sample entrepreneurs are males while $40 \%$ represent females. At least a small proportion of each category of gender has been represented thus suggesting that entrepreneurial activities are not dominated by one set of gender. Many (87.5\%) of these entrepreneurs are married. About $73.3 \%$ of them have at least basic education. This will enable them to read and understand training manuals for business development. Details of the summary statistics are shown in Table 3. 
Table 2: Variables definitions, units of measurement and hypothesized relationships

\begin{tabular}{llll}
\hline Variable & Definition & Unit of measurement & $\begin{array}{l}\text { Expected } \\
\text { Sign }\end{array}$ \\
\hline \multicolumn{1}{c}{$P_{i}$} & Participation & $\begin{array}{l}\text { If an ith entrepreneur has ever participated in a } \\
\text { training programme then 1; else 0 }\end{array}$ \\
GEN & Gender & Dummy (If male then 1; else 0) & $+/-$ \\
AGE & Age & Years & $+/-$ \\
AGESQ & Age Square & Years & - \\
MARID & Marital Status & Dummy (If married then 1; else 0) & $+/-$ \\
HSIZE & Household Size & Number of persons in the household & + \\
EDU & Educational Status & Dummy (At least basic then 1; else 0) & + \\
EXP & Years of Experience & Years & + \\
EXPSQ & Experience Square & Years & - \\
ASSOC & Association & Dummy (If a member then 1; else 0) \\
CREDIT & Access to Credit & Dummy (If accessed credit then 1; else 0) & + \\
INFO & Source of Information & Dummy (If radio then 1; else 0) & + \\
\hline
\end{tabular}

Table 3: Summary Statistics

\begin{tabular}{lll}
\hline Variable & $\begin{array}{l}\text { Statistics } \\
\text { Freq }\end{array}$ & Percent \\
\hline Gender & 72 & 60.0 \\
Male & 48 & 40.0 \\
Female & & \\
Marital Status & 105 & 87.5 \\
Married & 15 & 12.5 \\
Single & & \\
Educational Status & 88 & 73.3 \\
At least basic education & 32 & 26.7 \\
No formal education & & \\
Access to credit & 44 & 36.7 \\
Yes & 76 & 63.3 \\
No & & \\
Membership to Business Association & 24 & 20.0 \\
Member & 96 & 80.0 \\
No membership & & \\
Source of Business Information & 51 & 42.5 \\
Radio & 69 & 57.5 \\
Television & & \\
Participation in Training Program & 18 & 15.0 \\
Ever participated & 102 & 85.0 \\
Never participated & Mean & Std. Deviation \\
Age of entrepreneur & 34.58 & 6.92 \\
Household size & 5.71 & 2.59 \\
Years of business experience & 8.30 & 4.97 \\
\hline
\end{tabular}

It was observed from the survey that rural entrepreneurs in the East Mamprusi District engage in different kinds of SMEs to earn a living. Fifteen (15) different kinds of businesses were identified. They include: Sale of Provisions (53.3\%), Food vender (8.3\%), Shea butter extraction (6.7\%), Tailoring (6.6\%) Barbering (5.8\%), Boutique (5.0\%), Mechanics (2.5\%), Sale of animals (2.5\%), Bakery (1.7\%), Sale of Mobile phone credit $(1.7 \%)$, Hair dressing (1.7\%), Sale of drinks (0.8\%), Sale of motor spare parts (1.7\%), Cosmetics (0.8\%), and Electricals $(0.8 \%)$. Out of the 120 observation, only 18 entrepreneurs representing $15 \%$ of the sample ever attended a training program. This suggests that many (85\%) of them are likely to be operating with 
rudimentary technology and skills. Logistic regression was run to identify drivers for participation in the training programs. Entrepreneur's decision to participate or not was regressed on 11 covariates. They include: GEN, AGE, AGESQ, MARID, HSIZE, EDU, EXP, EXPSQ, ASSOC, CREDIT and INFO. The logistic regression output is presented in Table 4. The regression results in Table 4 shows a Likelihood Ratio Statistic of chi2 $(11)=52.65$ which is significant at less than $1 \%$. This implies that the decision to participate in a training program or not is jointly explained by the set of covariates. Eight (8) out of the 11 covariates were observed to have a significant influence on the probability of participation. They include GEN, AGE, AGESQ, EDU, EXP, EXPSQ, ASSOC and INFO. All the significant variables are in conformity with the a priori expectation.

Table 4: Logistic Regression Estimates of Participation in Training Programmes

\begin{tabular}{|c|c|c|c|c|}
\hline Variable & Coefficient & Standard Error & P-value & Marginal Effect \\
\hline Constant & -36.1450 & 13.6671 & 0.008 & \\
\hline $\mathrm{GEN}^{* * *}$ & -4.2740 & 1.1966 & 0.000 & -0.1038 \\
\hline $\mathrm{AGE}^{* *}$ & 1.3760 & 0.6711 & 0.040 & 0.0123 \\
\hline AGESQ** & -0.0186 & 0.0092 & 0.042 & -0.0002 \\
\hline MARID & -0.5397 & 1.7501 & 0.758 & \\
\hline HSIZE & 0.0768 & 0.1993 & 0.700 & \\
\hline $\mathrm{EDU}^{* * *}$ & 4.0121 & 1.4212 & 0.005 & 0.0253 \\
\hline EXP* & 1.5199 & 0.7952 & 0.056 & 0.0135 \\
\hline EXPSQ* & -0.0768 & 0.0392 & 0.051 & -0.0007 \\
\hline $\mathrm{ASSOC}^{* * *}$ & 3.0972 & 1.1494 & 0.007 & 0.0927 \\
\hline CREDIT & -0.0652 & 0.9072 & 0.943 & \\
\hline INFO** & 1.0894 & 0.4528 & 0.016 & 0.0097 \\
\hline
\end{tabular}

$* * *, * *=$ significant at $10 \%, 5 \%$ and $1 \%$ respectively

Consistent with previous studies, the effect of gender was found to have a significant influence on an entrepreneur's decision to participate in a business training program. From Table 4, the coefficient of gender is negative and significant at $1 \%$. This suggests that male entrepreneurs are associated with higher likelihood of participating in business training program than females. The marginal effect is $10.38 \%$ implying that being a male entrepreneur is associated with $10.38 \%$ probability of participation higher than a female entrepreneur. Several explanations could be given to this observation. Men generally have more passion in discovering new ideas and are associated with risk loving behaviors than females. This may entice them to participate more than females. Besides, households in East Mamprusi District share the culture of male dominance in decision making. Females can attend social programs only when they seek approval from household heads. This element of culture has the potential of limiting their participation in entrepreneurial training programs.

Age was also observed to have a significant relation with the likelihood of participating in entrepreneurial development programs. From Table 4, the coefficient of age is positive and significant at $5 \%$. Its marginal effect is $1.23 \%$ suggesting that age of respondent moves directly with the probability of participation. Every additional year attracts $1.23 \%$ probability of participation. However, when age was squared, the effect became negative and significant at 5\%. Contrary to Fritsche (2012) observation in Germany, the result of this study provides an inverted U-shape effect of age on participation. This implies that participation increases with age to a particular point and then begins to decline. The justification for this result is that participation will increase during youthful ages and will begin to fall gradually during old ages. The effect of education; measured by whether an entrepreneur has at least basic formal education has a significantly positive influence on participation in business training program. From Table 4, its coefficient is positive and significant at $1 \%$. This implies that entrepreneurs with at least basic formal education have higher likelihood of participation than those without basic formal education. The marginal effect of education is $2.50 \%$ which implies that the probability of people with formal education to participate is $2.5 \%$ more than those without any form of formal education. This agrees with Xiao and Tsang (2001), Turcotte et al. (2002) and Fritsche (2012) people with formal education are associated with higher likelihood of participation in entrepreneurial skills development training. People with formal education can read and understand current activities from 
different sources such as the media and training manuals. This has a potential in increasing their probability of participation.

In addition, the experience of the entrepreneur measured by the number of years individuals have being in their respective businesses. From Table 4, the coefficient of experience is positive and significant at $10 \%$. This suggest that the probability to participate in a training program increase with experience. For any additional year of experience the probability of participation increases by $1.35 \%$. The square of experience yields a quadratic and significant effect. This implies that the desire to go for skills development training increases in the initial years in business but declines thereafter. The justification is that past experiences could make them complacent, thus discouraging them from participation in skills development training programs. People often join social groups to have a common objective for their own development. Specific objectives of such association often include easy access to affordable inputs, training and marketing services. It was observed that membership to an association has a significant and positive effect on the probability of participation. From Table 4, its coefficient is significant at $1 \%$ with marginal effect of $9.27 \%$. This implies that being a member to an association is associated with $9.27 \%$ of participation higher than non-members. Information on the time and kind of training programs may be shared at group meeting to increase participation rate.

The role of media in information dissemination is important in entrepreneurial activities. Radio announcements and Television programs constitute the main source of information. It was observed from the survey that entrepreneurs whose main source of information is radio tend to have higher probability of attending training programs than those who rely much on television (see statistics in Table 4). Many people have radios than televisions given the relatively higher cost of television. This grants people access to business information via radio. Radio announcements in the district are also presented using local languages which many of the entrepreneurs understand better. This explains the likelihood of accessing information from radio than television in the study area.

\section{Conclusion and Recommendations}

Small and medium scale enterprises operate in the East Mamprusi District in different fields. Fifteen of them have been identified from the findings of this study. It was however, realized that about $85 \%$ of owners of these business fail to attend entrepreneurial skills development training despite institutional efforts to deliver these services with little or no financial cost. Several factors were therefore, identified to have significant influence on the likelihood of participation. They include entrepreneur's socio-demographic features, access to services and past experience acquired in their business operations. This paper argues that despite Government, Civil Society Organization and Non-governmental Organizations' effort to sharpen skills and increase productivity of Small and Medium Scale Enterprises by providing training intervention to all parts of the country, entrepreneurs' participation in these programs in the hinterland is believed to be low. Therefore, the researchers believe that policy makers could use the factors identified in this paper in formulating and implementing strategies toward entrepreneurial skills development especially in the informal sector of least developed countries. It is therefore, recommended that Government, Nongovernmental Organizations and Civil Society Organizations should put more effort in widening the scope of participation in entrepreneurial skills development training. Appropriate attention should be given to gender, age, education, past experience, membership of association and media of advertisement since they are all factors that drive entrepreneurial motivation to participate in training programs. Rural entrepreneurs should develop the initiative to form associations where information on training needs can easily reach them. Any training intervention should also target young entrepreneurs to have more participants.

Acknowledgement: The authors acknowledged Mr. Bariche David Bukari (a post graduate student of the School of Business and University for Development Studies, Wa-Campus) for his assistance in designing the questionnaire and data collection. 


\section{References}

Akanbi, S. T. (2013). Familial Factors, Personality Traits and Self-Efficacy as Determinants of Entrepreneurial Intention among Vocational Based College Of Education Students in Oyo State, Nigeria. The African Symposium: An online journal of the African Educational Research Network, 13(2).

Aremu, M. A. \& Adeyemi, S. L. (2011). Small and Medium Scale Enterprises as A Survival Strategy for Employment Generation in Nigeria. Journal of Sustainable Development, 4(1).

Audretsch, D. B. (2012). Determinants of High-Growth Entrepreneurship. Report prepared for the OECD/DBA International Workshop on -High-growth firms: local policies and local determinants, Copenhagen, 28 March 2012.

Baah-Boateng, W. (2004). Employment Policies for Sustainable Development: The Experience of Ghana. A paper presented at a national workshop on an employment Framework for Ghana's poverty reduction strategy Organized by Government of Ghana/UNDP/ILO on May 7, 2004 at Golden Tulip, Accra

Bascavusoglu-Moreau, E., Kopera, S. \& Wszendybył-Skulska, E. (2013). The Role of Creativity in Development of Innovation in Tourism. Journal of Entrepreneurship Management and Innovation, 9(1).

Beer, A. D. (2012). An analytical report on: An entrepreneurship training program for 75 Ghanaian women. Prepared for the Association of African Entrepreneurs

Commonwealth Secretariat. (2010). Strengthening Business Development Services Provision in Ghana. Marlborough House, Pall Mall London SW1Y 5HX

Cooney, T. M. (2012). Entrepreneurship Skills for Growth-Orientated Businesses. Report for the Workshop on 'Skills Development for SMEs and Entrepreneurship, Copenhagen, 28 November 2012

East Mamprusi District Assembly (2012). The Composite Budget of the East Mamprusi District assembly for the 2012 fiscal year. Republic of Ghana.

Ercan, H., Hoşgör, A. G. \& Yılmaz, Ö. (2010). Factors That Affect Women's Labor Force Participation and Suggestions for Provincial Employment and Vocational Education Boards: Ankara, Gaziantep, and Konya.

European Commission. (2009). Entrepreneurship in vocational education and training. European Commission

Fritsche, S. (2012). Determinants of training participation: A literature review and empirical support from personal-, job-, employer- and health related factors in Germany. MSc Thesis 2012-025

Garba, A. S., Djafar, F. \& Mansor, S. A. (2013). Evidence of Opportunity and Necessity Driven Entrepreneurship in Nigeria. Journal of Entrepreneurship Management and Innovation, $9(3)$.

Ghana Statistical Service. (2008). Ghana Living Standards Survey, Report of the Fifth Round. Republic of Ghana Statistical Service, Accra, Ghana

Glaub, M. \& Frese, M. (2011). A critical review of the effects of entrepreneurship training in developing countries. Enterprise Development \& Microfinance, 22, 335-353.

Hassan, I. B. \& Mugambi, F. (2013). Determinants of Growth for Women Owned and Operated Micro Enterprises: The Case of Garissa, Kenya. International Journal of Business and Commerce, 2(7), 4555.

Heckman, J. J. \& Smith, J. (2003). The Determinants of Participation in a Social Program: Evidence from a Prototypical Job Training Program. CIBC Working Paper Series \# 2003-4

Henriquez, C., Verheul, I., van der Knaap, I. \& Bischoff, C. (2001). Determinants of Entrepreneurship in France: Policies, Institutions and Culture. The Institute for Development Strategies, Indiana University.

Hui, T. S. \& Smith, J. A. (2001). The Determinants of Participation in Adult Education and Training in Canada. Munich Personal RePEc Archive (MPRA) Paper No. 17998

Hussain, M. D., Bhuiyan, A. B. \& Bakar, R. (2014). Entrepreneurship Development and Poverty Alleviation: An Empirical Review. Journal of Asian Scientific Research, 4(10), 558-573

Joseph L. (2010). Promoting Micro and Small Scale Industries for Local Development in Ghana: The Case of East Mamprusi District. Thesis submitted to the Department of Planning, Kwame Nkrumah University of Science and Technology, Kumasi, in partial fulfillment of the requirements for the degree of MASTER OF SCIENCE Development Planning and Management Faculty of Planning and Land Economy College of Architecture and Planning 
Kayanula, D. \& Quartey, P. (2000). The policy environment for promoting small and medium-sized enterprises in Ghana and Malawi. Finance and Development Research Program Working Paper Series Paper No 15

Lashgarara, F., Roshani, N. \& Najafabadi, O. (2011). Influencing Factors on Entrepreneurial Skills of Rural Women in Ilam City, Iran. African Journal of Business Management, 5(4), 5536-5540.

Mark, A. K. (2012). Promoting Micro and Small Scale Industries in Ghana for Local Development: A Case Study of the Rural Enterprises Project in Asante Akim South District. Thesis submitted to the Institute Of Distance Learning, Kwame Nkrumah University of Science and Technology.

Mensah, S. (2004). A Review of SME Financing Schemes in Ghana. Presented at the UNIDO Regional Workshop of Financing Small and Medium Scale Enterprises, Accra, Ghana, 15-16 March 2004

MoFA. (2007). Food and Agricultural Sector Development Policy, (FASDEP II) August, 2007.

Papzan, A., Afsharzade, N. \& Moradia, K. (2013). Entrepreneurial Intention Determinants: An Empirical Model and a Case of Iranian Students in Malaysia. Journal of Entrepreneurship Management and Innovation, $9(3)$.

Quartey, P. (2003). Financing Small and Medium Enterprises (SMEs) in Ghana. Journal of African Business, $4(1)$

Todaro, M. P. \& Smith, S. C. (2009). Economic Development (10th ed), Perason Education Ltd, Harlow: England

Turcotte, J., Léonard, A. \& Montmarquette, C. (2002). New Evidence on the Determinants of Training in Canadian Business Locations. Applied Research Branch Strategic Policy Human Resources Development Canada.

Vijayalakshmi, P. S. (2014). Beneficiaries Perception towards Entrepreneurship Development Program. Indian Journal of Applied Research, 4(10)

Xiao, J. \& Tsang, M. C. (2001). Determinants of On-the-job Training and Adult Education in Shenzhen, China. Presented at International Conference on Economics of Education Beijing University, Beijing, China May 16-19, 2001 